\title{
Evaluation of the Flamelet/Progress-Variable Approach and Flamelet-Generated Manifolds Method in Laminar Counter-Flow Diffusion Flame
}

\author{
Yohsuke Matsushita ${ }^{* 1 \dagger}{ }^{\dagger}$, Ryoma OzaWA ${ }^{* 2}$, Shota AKAotsu*2, Yoshiya Matsukawa ${ }^{* 2}$, \\ Yasuhiro SAITO ${ }^{* 3}$, Hideyuki AOKI ${ }^{* 2}$, and Weeratunge MALALASEKERA $* 4$ \\ (Received June 10, 2020)
}

\begin{abstract}
To evaluate characteristics of the Flamelet/Progress-Variable approach (FPV) and Flamelet-Generated Manifolds method which can consider a detailed chemical reaction mechanism, a combustion simulation was performed in a laminar counter-flow diffusion flame. While the numerical solutions of the FPV reproduced the measurements and almost completely agreed with those of the detailed chemical reaction mechanism, the numerical solutions of the FGM method overpredicted the measurements of $\mathrm{CO}$ mole fraction and underpredicted the ones of $\mathrm{CO}_{2}$ especially in fuel-rich region, and differed from those of the detailed chemical reaction mechanism. This is because the flamelet table of the FGM indicates the state close to chemical equilibrium and overpredicts dissociation of $\mathrm{CO}_{2}$ when the combustion reaction sufficiently progresses.
\end{abstract}

詳細化学反応機構を考慮可能な乱流燃焼モデルであるFlamelet/Progress-Variable approach (FPV) と FlameletGenerated Manifolds method (FGM) の特徴を把握することを目的に，対向流拡散火炎を対象とした燃焼シミュレーションを実施 した FPV の数值解は測定值を再現し, 詳細化学反応機構の数值解とほほほほぼ完全に一致した。一方, FGM の数值解は測定 結果と比較して燃料過濃領域に执いて $\mathrm{CO}$ のモル分率を過大に, $\mathrm{CO}_{2}$ のモル分率を過小に評価し, 詳細化学反応機構の数值解 と差異を生じた。これは，FGMの flamelet table が燃焼反応の十分に進行した状態では化学平衡に近い状態を示し, $\mathrm{CO}_{2}$ の解 離を過大に評価するためである。

\section{Key Words}

Combustion Simulation, Flamelet/Progress-Variable approach, Flamelet-Generated Manifolds method, Counter-flow diffusion flame

\section{Introduction}

One of the numerical methods for fluid flow computation with chemical reactions such as combustion is to directly solve the conservation equations of chemical species including radical species. Although chemical reactions and fluid motion which are significantly different in their time scales can be solved simultaneously, the number of conservation equations of chemical species to be considered is huge and a small time increment should be applied according to chemical reactions whose time scale is small, thus a computational effort of this method is found to be significantly high. For example, 53 chemical species and 325 chemical reactions are included in the detailed chemical reaction mechanism, the GRI-Mech 3.0 ${ }^{1)}$

\footnotetext{
※3 Department of Applied Chemistry, Kyushu Institute of Technology 1-1 Sensuicho, Tobata-ku, Kitakyushu-shi, Fukuoka 804-8550, Japan

※4 Wolfson School of Mechanical, Electrical and Manufacturing Engineering, Loughborough University Loughborough, Leicestershire LE11 3TU, UK

† Corresponding author: matsushita@hirosaki-u.ac.jp
} 
which is the most popular for combustion of the simplest hydrocarbon, methane. Furthermore, to our best knowledge, when a turbulent combustion simulation based on the Reynolds-Averaged Navier-Stokes equations or Large Eddy Simulation is performed, although the term of chemical reaction rate which appears in the conservation equations of chemical species should be averaged in time or space, its methodology has not been established yet.

The flamelet approach is a combustion model which can consider a detailed chemical reaction mechanism although indirectly and can be performed with a low computational effort by separating chemical reactions and fluid motion whose time scales are significantly different. Specifically, prior to a target combustion simulation, combustion in a simple system in which a detailed chemical reaction mechanism can be used is numerically analyzed and all of the interesting variables such as temperature, chemical species concentration and properties of mixture are saved in the database called the flamelet table with respect to mixture fraction and a reaction progress variable. In a target combustion simulation, only the conservation equations of mixture fraction and a reaction progress variable are solved and other variables are determined by looking up the flamelet table using these parameters without solving the conservation equations of chemical species and enthalpy. Therefore, since the number of conservation equations to be solved does not increase in a target combustion simulation even when the number of chemical species and chemical reactions included in a detailed chemical reaction mechanism increases and a large time increment can be applied according to fluid motion whose time scale is large, a computational effort in this method is found not to be particularly high. The flamelet table is generated for the one-dimensional counter-flow diffusion flame in the flamelet model ${ }^{23}$ ) or Flamelet/Progress-Variable approach (FPV) ${ }^{4)}$ whereas the one is for the one-dimensional premixed flame in the Flamelet-Generated Manifolds method (FGM) ${ }^{5)}$ ). Thus, the flamelet model and the FPV have been used for diffusion combustion while the FGM has been for premixed combustion, respectively. These combustion models have been developed ${ }^{7)}{ }^{8)}$ and have also been applied to spray and pulverized coal combustion ${ }^{9)} \sim 11$. Each characteristic of diffusion and premixed combustion has been known to appear, needless to say in partially-premixed combustion, in spray combustion and pulverized coal combustion. Therefore, a combustion model which can express diffusion and premixed combustion seamlessly is desired. Recently, the combustion simulation in which the FPV and FGM are linearly-combined has been conducted by using a parameter called the Flame Index which can distinguish diffusion and premixed combustion in a local combustion field ${ }^{12)}{ }^{13)}$. For the purpose of the universal modeling, the information for the performance and limitation of the FGM method for diffusion flame would be desired. From our results for the typical diffusion flame, the FGM only seems to be insufficient to capture the diffusion flame characteristics. In contrast, the information for the performance and limitation of the FPV for premixed flame would be necessary in future. Knowing the information for the performance and limitation of the FGM and FPV for diffusion and premixed flame, respectively promises to help developing the seamless modeling.

In this study, a combustion simulation is performed for the counter-flow diffusion flame ${ }^{14)}$ by using the FPV and FGM, which are widely used especially among the flamelet approaches. The characteristics of the FPV and FGM are evaluated by comparing these numerical solutions with the measurements and numerical solutions with the detailed chemical reaction mechanism. The numerical solution with the detailed chemical reaction mechanism is mainly used to verify the flamelet approaches such as the FPV and FGM can reproduce the solution with the detailed chemical reaction mechanism and the measurements are to confirm the flamelet approaches provide the realistic solutions.

\section{Analytical object}

To test or verify the flamelet approaches such as the flamelet/progress-variable (FPV) approach or flameletgenerated manifolds (FGM) method, it is the well-established procedure to compute the two- or three-dimensional flame using the FPV or FGM and compare their numerical solutions with experiments and/or the numerical solutions obtained by using the detailed chemical reaction mechanism employed in generating the flamelet table. To minimalize the number of factors affecting the numerical solutions, laminar jet or counter-flow diffusion flames with the measurements are usually chosen. To simulate the flame with the detailed chemical reaction mechanism, the twodimensional system with the smaller number of grids is desired because the computational effort with the detailed chemical reaction mechanism is extremely high. From the above reasons, we selected the counter-flow diffusion flame shown in Fig. 1. C. Sung et al. ${ }^{14)}$ measured temperature and mole fraction of chemical species between oxidizer and fuel nozzles by changing strain rate as $a=42,56$, and $90 \mathrm{~s}^{-1}$ for oxidizer mixture of $\mathrm{O} 2: \mathrm{N} 2=0.23: 0.77$ and fuel one of $\mathrm{CH}_{4}: \mathrm{N}_{2}$ $=0.23: 0.77$ in mole at temperature of $300 \mathrm{~K}$ in the laminar counter-flow diffusion flame. In this study, the counter-flow diffusion flame under the condition for strain rate of $a=$ 


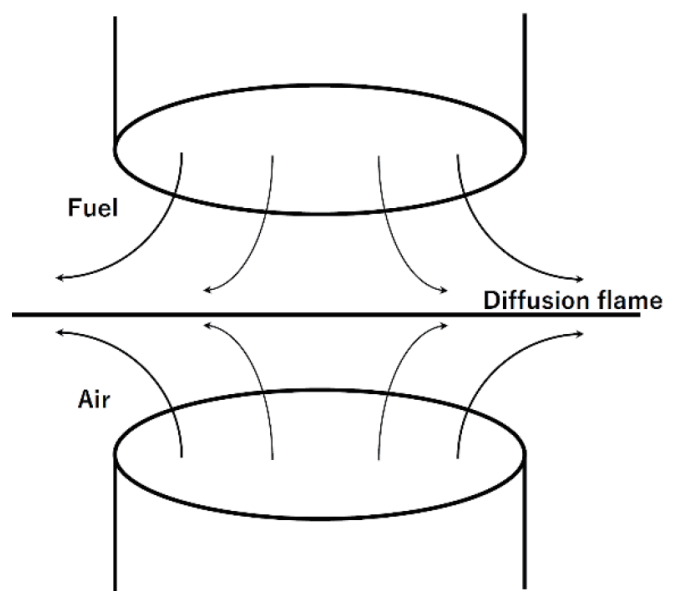

Fig. 1 Schematic diagram of counter-flow diffusion flame

$42 \mathrm{~s}^{-1}$ was numerically analyzed as a target. It should be noted that although another strain rate for $a=56$ or $90 \mathrm{~s}^{-1}$ was also tested, we concentrate to discuss the results with strain rate for $a=42 \mathrm{~s}^{-1}$ because the overall trend was similar among them.

\section{Numerical procedure}

\subsection{The flamelet approach}

In the flamelet approach represented by the flamelet model ${ }^{2)}$ ), a combustion simulation for diffusion flame is conducted using a detailed chemical reaction mechanism indirectly by regarding diffusion flame as a collection of laminar flamelet. In this model, chemical reactions and fluid motion are separated by using a large difference in their time scales. Also, this model uses mixture fraction which presents mixture of oxidizer and fuel and scalar dissipation rate as parameters to characterize combustion. Specifically, prior to the target combustion simulation, the onedimensional counter-flow diffusion flame was numerically analyzed for various scalar dissipation rates by changing strain rate, for example, distance between oxidizer and fuel nozzles, and then all of the variables such as temperature, chemical species concentration and properties such as density of mixture are saved into the database called the flamelet table as functions of mixture fraction and scalar dissipation rate. In the target combustion simulation, the conservation equation of mixture fraction is solved and scalar dissipation rate is algebraically calculated, and then all of the interesting variables are determined by looking up the flamelet table using mixture fraction and scalar dissipation rate obtained. Therefore, a combustion simulation in which a detailed chemical reaction mechanism is reflected though indirectly can be performed without solving conservation equations of enthalpy and chemical species.
In this study, the GRI-Mech $3.0^{1)}$ including 53 chemical species and 325 chemical reactions, which is the most supported in methane combustion, was employed for the detailed chemical reaction mechanism and the FlameMaster code ${ }^{15)}$ with our slight modification was used to numerically analyze the one-dimensional laminar counter-flow diffusion flame in the mixture fraction space or premixed flame in the physical space described below. The details of their solutions can be found in the literature ${ }^{15)}$. It should be noted that Lewis number was assumed to be constant and equal to unity and effect of radiation heat transfer was ignored since flame thickness is small, which are the common assumptions employed in the flamelet approaches.

\subsubsection{The Flamelet/Progress-Variable approach (FPV)}

The characteristic of the Flamelet/Progress-Variable approach (FPV) ${ }^{4}$ is that it can express unstable combustion state which cannot be uniquely determined with scalar dissipation rate in addition to stable combustion state described in the flamelet model. Although the flamelet table is generated for counter-flow diffusion flame as is the same in the flamelet model, the FPV is different from the flamelet model from the point of view that a parameter to characterize combustion is not scalar dissipation rate but a reaction progress variable called the Progress Variable (PV). In this study, the PV is defined as the summation of mass fraction of $\mathrm{CO}, \mathrm{CO}_{2}, \mathrm{H}_{2}$, and $\mathrm{H}_{2} \mathrm{O}$. Specifically, the one-dimensional counter-flow diffusion flame was analyzed for various scalar dissipation rates as is the same in the flamelet model and the variables including the net production rate of the PV are saved in the flamelet table as functions of mixture fraction and the PV by converting scalar dissipation rate to the PV after the variables are evaluated with respect to mixture fraction and scalar dissipation rate.

As an example of the flamelet table of the FPV, Fig. 2

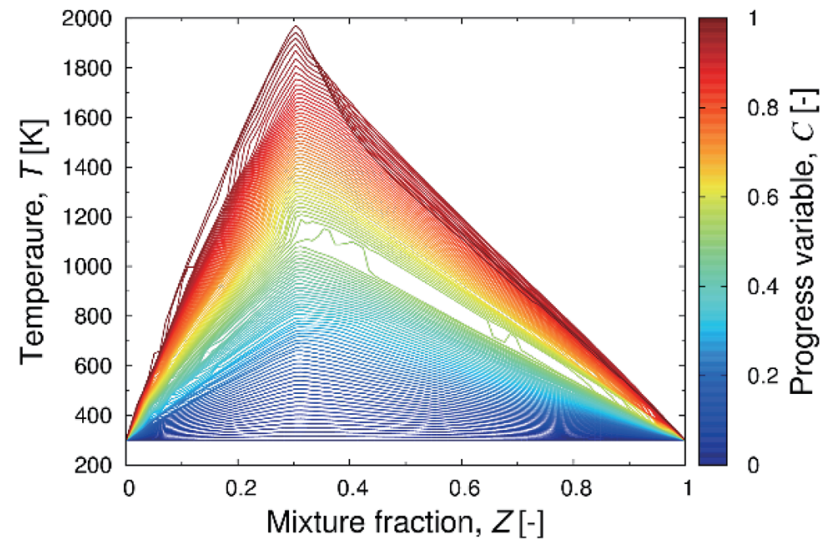

Fig. 2 The flamelet table of temperature generated with the FPV 
displays the flamelet table of temperature as functions of mixture fraction and the PV for the counter-flow diffusion flame of Sung et al. ${ }^{14)}$. Temperature is given with respect to mixture fraction and PV, indicating that temperature can be uniquely determined. In the target combustion simulation, the conservation equations of mixture fraction and the reaction progress variable are solved, and other variables are determined by looking up the flamelet table using them. The generation procedure of the flamelet table of the FPV is explained in our review article ${ }^{16)}$ in detail.

\subsubsection{The Flamelet-Generated Manifolds method (FGM)}

The Flamelet-Generated Manifolds method (FGM) ${ }^{5)}$ is different from the flamelet model and FPV in generating the flamelet table not from the one-dimension counter-flow diffusion flame but from the one-dimensional premixed flame. Now, an application of the FGM to a simulation for diffusion combustion is considered. Specifically, prior to the target simulation, the one-dimensional premixed flame was numerically analyzed for various equivalence ratio and then the variables including the net production rate of Controlling Variable (CV) are saved in the flamelet table by converting distance to a reaction progress variable called the $\mathrm{CV}$ and equivalence ratio to mixture fraction, respectively. Although the PV and CV are different in their names, they are essentially the same parameters. Equivalence ratio is converted to mixture fraction using Eq. (1):

$$
Z=\left[1+\frac{1-Z_{\mathrm{st}}}{Z_{\mathrm{st}} \phi}\right]^{-1}
$$

where $Z_{\text {st }}$ is mixture fraction at stoichiometric ratio and $Z_{\text {st }}$ $=0.30$ in the counter-flow diffusion flame of Sung et al. ${ }^{14)}$. Fig. 3 indicates the relationship between equivalence ratio and mixture fraction for the flame. One-to-one relationship between equivalence ratio and mixture fraction is established, indicating that equivalence ratio can be

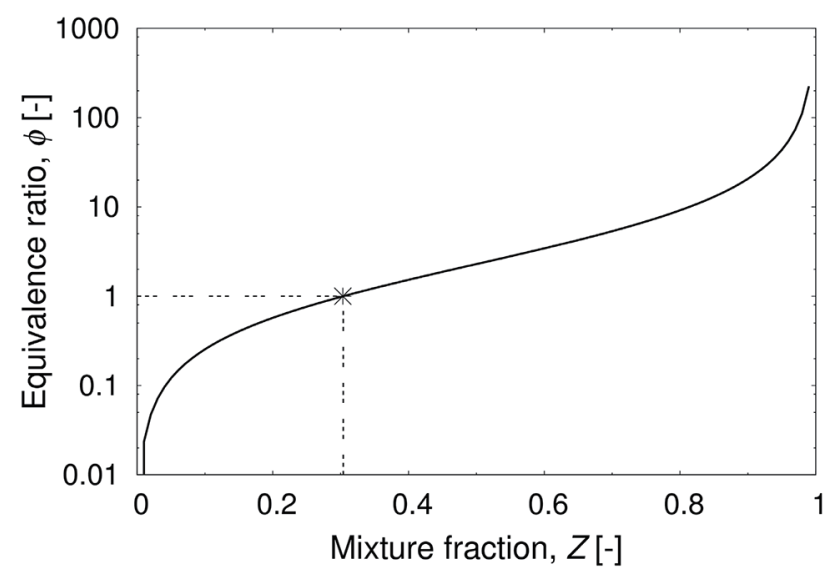

Fig. 3 The relationship between equivalence ratio and mixture fraction converted to mixture fraction. Also, the combustible range is $0.50<\phi<1.68$ in equivalence ratio and $0.18<Z<0.42$ in mixture fraction. However, the numerical analysis for the one-dimensional premixed flame could be conducted without extinction for equivalence ratio of $0.26<\phi<6.90$ corresponding to mixture fraction of $0.10<Z<0.75$, which is out of combustible range when the GRI-Mech 3.0 ${ }^{1)}$ was used for a detailed chemical reaction mechanism. In this study, the flamelet table was generated by using the results only within combustible range. The other variables out of the combustible range were obtained by linear-interpolation. It was confirmed that almost the same outline was obtained even when the flamelet table was generated by using all the variables within the range in which the numerical analysis could be carried out.

As an example of the numerical solutions in the combustion simulation for the one-dimensional premixed flame, Fig. 4 shows the distributions of temperature and mole fraction of major chemical species for equivalence ratio of unity. As combustion progresses, temperature was elevated, $\mathrm{O}_{2}$ and $\mathrm{CH}_{4}$ were consumed, $\mathrm{CO}$ increased and decreased, and $\mathrm{CO}_{2}$ and $\mathrm{H}_{2} \mathrm{O}$ are produced. Also, Fig. 5 plots the same distributions shown in Fig. 4 but for the CV converted from distance, indicating that temperature and mass fraction of chemical species can be expressed by the $\mathrm{CV}$. As it the same in the FPV, the reaction progress variable of the $\mathrm{CV}$ is defined as the summation of mass fractions for $\mathrm{CO}, \mathrm{CO}_{2}, \mathrm{H}_{2}$, and $\mathrm{H}_{2} \mathrm{O}$, which has been widely employed for fuel of hydrocarbon. Further, Fig. 6 displays temperature for mixture fraction and the CV by obtaining the numerical solutions for other equivalence ratio as well and converting equivalence ratio to mixture fraction by using Eq. (1). It should be noted that a series of plots lying parallel to the vertical axis is temperature in the one-

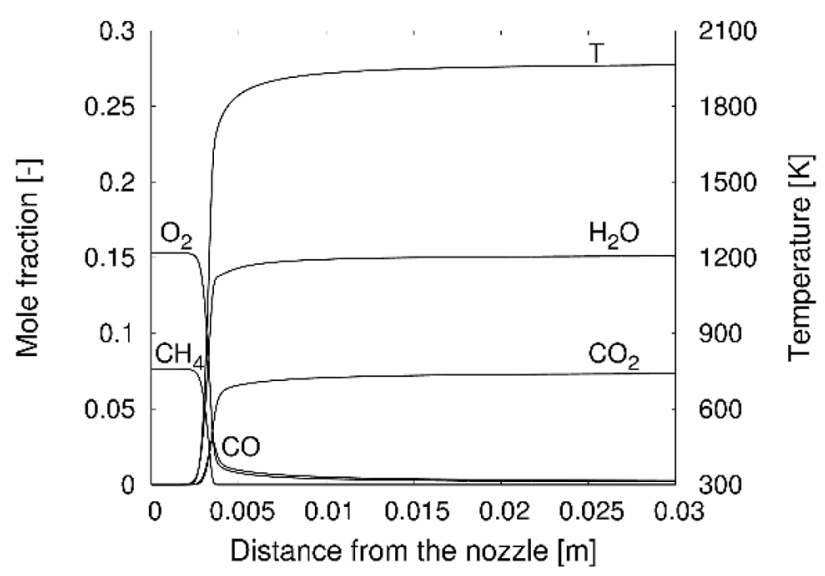

Fig. 4 Mole fraction distributions for distance in the onedimensional premixed flame at stoichiometric ratio 


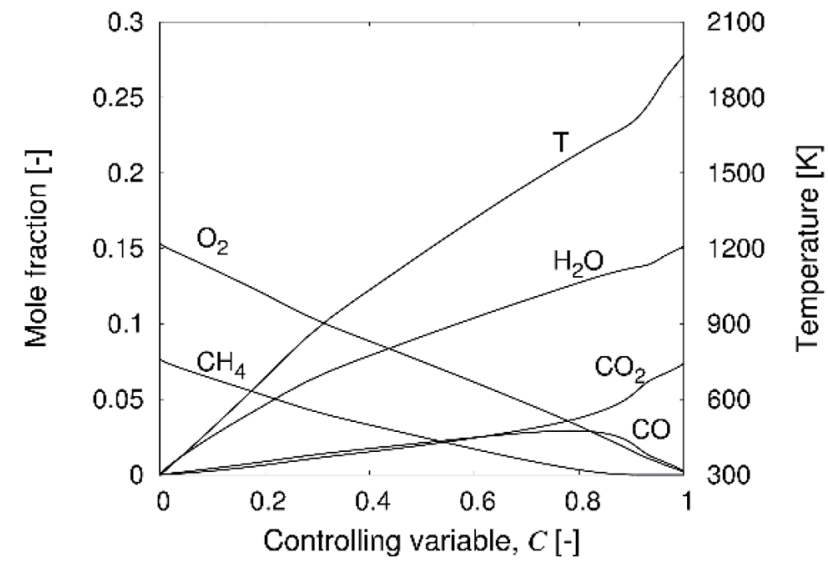

Fig. 5 Mole fraction distributions for the controlling variable as a reaction progress variable in the one-dimensional premixed flame at stoichiometric ratio

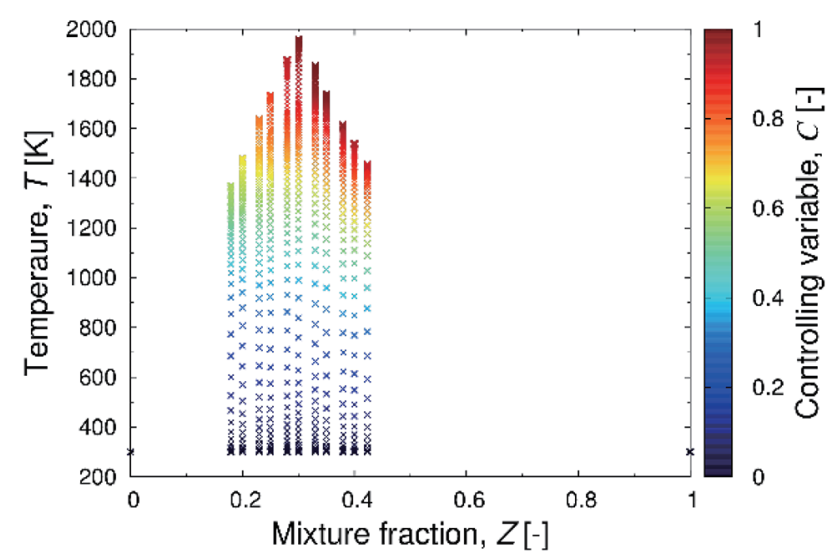

Fig. 6 Temperature distributions for mixture fraction and the controlling variable as a reaction progress variable within the combustible range

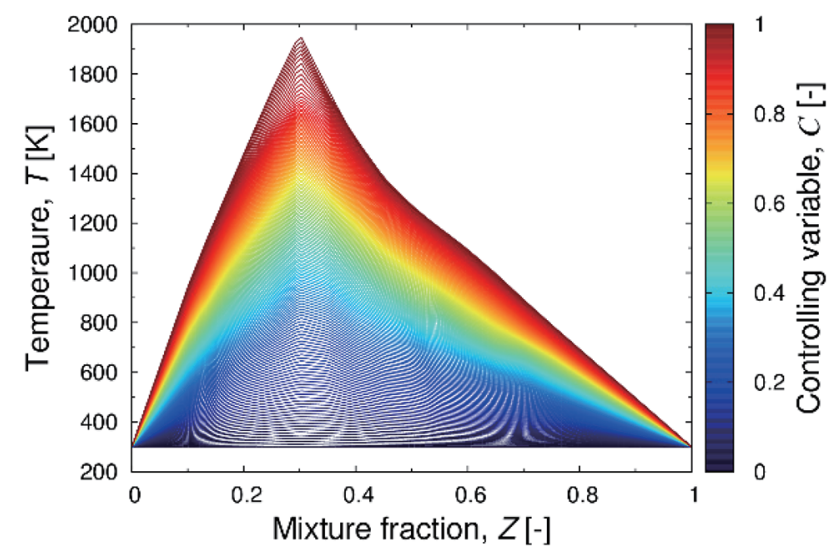

Fig. 7 The flamelet table of temperature generated with the FGM

dimensional premixed flame for each equivalence ratio, and higher temperatures are found for larger values of the CV. Finally, as an example of the flamelet table of the FGM, Fig. 7 displays the flamelet table of temperature as functions of mixture fraction and the $\mathrm{CV}$. As is the same in the FPV, temperature is given with respect to mixture fraction and $\mathrm{CV}$, demonstrating that temperature can be uniquely determined. Also, the outline in the flamelet table of the FGM is quite similar to that of the FPV shown in Fig. 2, suggesting that is can be applicable to a combustion simulation of diffusion combustion. In the target combustion simulation, the conservation equations of mixture fraction and the reaction progress variable are solved, and then other variables are determined by looking up the flamelet table using them. Since the flamelet table is generated with the one-dimensional premixed flame, the characteristics of the premixed combustion rather than the diffusion one would strongly appear.

\subsection{Governing equations and their solutions}

The combustion simulation based on the Flamelet/ Progress-Variable approach or Flamelet-Generated Manifolds method is performed for the region which was uniformly divided into $130 \times 130$, which is sufficient fine to discuss the numerical solutions without mesh dependency, between the oxidizer and fuel nozzles under the condition for strain rate of $a=42 \mathrm{~s}^{-1}$ in the counter-flow diffusion flame of C. Sung et al. ${ }^{14}$. It is not sufficient to simulate the one-dimensional counter-flow diffusion flame because the fluid flow is "fixed" by prescribing fluid flow leaving the system according to the strain rate. Therefore, it is better to compute the twoor three-dimensional flame using the FPV or FGM and compare their numerical solutions with experiments and/ or the numerical solutions obtained by using the detailed chemical reaction mechanism employed in generating the flamelet table. In this study, the two-dimensional simulation was conducted because no significant difference was found between the two- and three-dimensional simulations and the one with the detailed chemical reaction mechanism whose computational effort is extremely high is also performed. The inflow boundaries are given to the oxidizer and fuel nozzles and the outflow boundaries are prescribed to the other boundaries, respectively. In addition to the continuity equation and Navier-Stokes equations with the low-Mach number assumption, the conservation equations of mixture fraction, $Z$ and the reaction progress variable, $C$ described in Eqs. (2) and (3) are solved using our in-house code based on the unstructured finite volume method:

$$
\begin{aligned}
& \frac{\partial}{\partial t}(\rho Z)+\frac{\partial}{\partial x_{j}}\left(\rho Z u_{j}\right)=\frac{\partial}{\partial x_{j}}\left(\frac{\mu}{S c} \frac{\partial Z}{\partial x_{j}}\right), \\
& \frac{\partial}{\partial t}(\rho C)+\frac{\partial}{\partial x_{j}}\left(\rho C u_{j}\right)=\frac{\partial}{\partial x_{j}}\left(\frac{\mu}{S c} \frac{\partial C}{\partial x_{j}}\right)+\dot{\omega}_{C},
\end{aligned}
$$

where $\rho, \mu$, and $\dot{\omega}_{C}$ are density, viscosity, and net production rate of the reaction progress variable, respectively, and 
are determined by looking up the flamelet table using mixture fraction and the reaction progress variable obtained above. $S c$ is Schmidt number and constant value of 0.7 was given. Based on the unstructured finite volume method, the convection and diffusion terms in the NavierStokes equations and the conservation equations of mixture fraction and progress variable are discretized by the TVD scheme with the minmod limiter ${ }^{17)}$ and the 2nd-order central differential method, respectively. The Semi-Implicit Method for Pressure-Linked Equation (SIMPLE) algorithm ${ }^{18)}$ with the Rhie-Chow interpolation ${ }^{19)}$ is used for pressure solution and the steady-state computation is conducted for the combustion simulation with the FPV or FGM whereas the Simplified Marker And Cell (SMAC) method ${ }^{20)}$ is employed and unsteady-state calculation is performed with the detailed chemical reaction mechanism until the steadystate is archived.

\section{Results and discussion}

4.1 Temperature distributions obtained by the Flamelet/Progress-Variable approach and Flamelet-Generated Manifolds

Fig. 8 shows the spatial distributions of temperature between nozzles of oxidizer and fuel obtained by the combustion simulation based on the Flamelet/ProgressVariable approach (FPV) ${ }^{4)}$ and Flamelet-Generated Manifolds method (FGM) ${ }^{5)}$ under the condition for strain rate of $a=45$ $\mathrm{s}^{-1}$ in the counter-flow diffusion flame of Sung et al. ${ }^{14}$. High temperature field was formed in the region where oxidizer and fuel mixture met and stable flame existed regardless of the combustion models used. Thus, each combustion model would be able to roughly express the feature of the counter-flow diffusion flame. However, focusing on the flame temperature around the center between nozzles where high temperature filed was formed, the temperature in the FPV is slightly higher than that in the FGM. Hereby, the specific values which each model looped up in the flamelet table are investigated. Fig. 9 displays scatter plots of temperature for mixture fraction as the values the FPV and FGM looped up in the flamelet table at steady-state. Noted that the scatter plots are the values plotted for mixture fraction in all of the computational cells, which are looked up by using mixture fraction, $Z$ and the Progress Variable or Controlling Variable as a reaction progress variable, $C$ which are obtained by solving their conservation equations of Eqs. (2) and (3). Since relatively higher temperature in the flamelet table generated based of the FPV or FGM shown in Fig. 2 and Fig. 7 are plotted, the plots indicate the stable flame with steady-state or close to it at which combustion reaction significantly progresses. The above results suggest a difference in flame temperature where high temperature region was formed around the center between the nozzles would be caused by a difference in temperature looped up in the FPV and FGM.

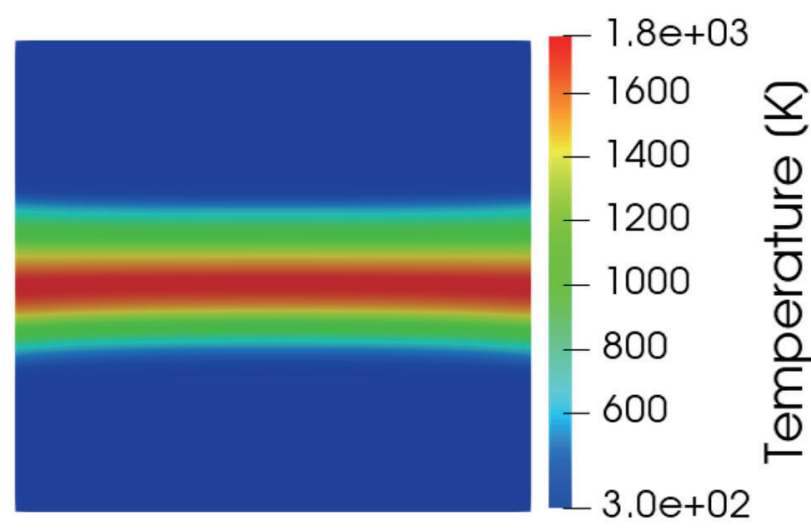

(a) with the Flamelet/Progress-Variable approach (FPV)

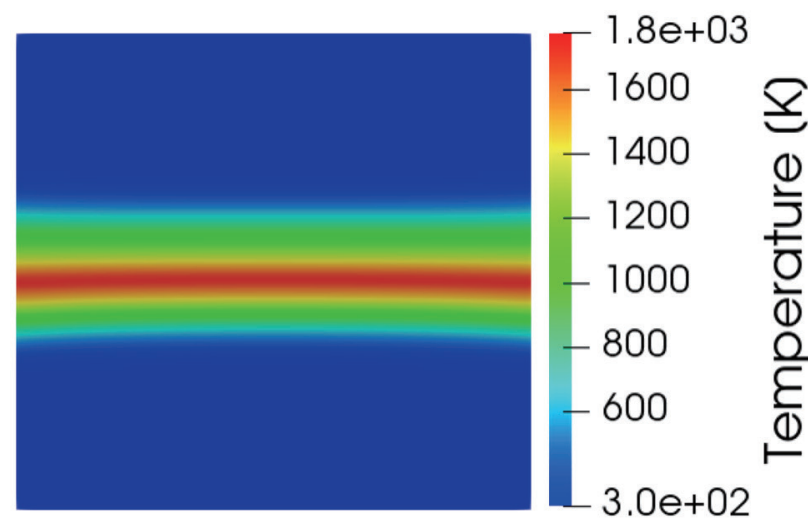

(b) with the Flamelet-Generated Manifolds (FGM)

Fig. 8 Spatial distributions of temperature between oxidizer and fuel nozzles at steady-state

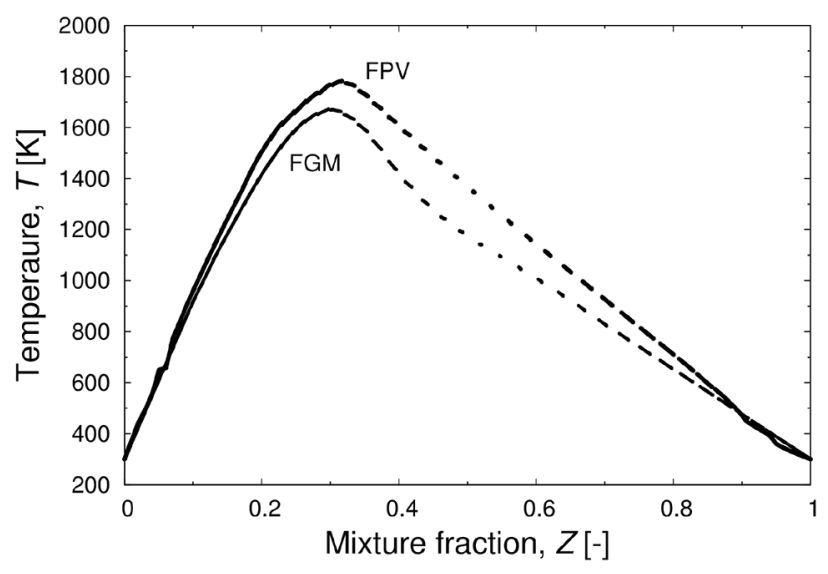

Fig. 9 Scatter plots of temperature for mixture fraction with the FPV and FGM 


\subsection{Comparison of numerical solutions of the Flamelet/ Progress-Variable approach and Flamelet- Generated Manifolds method with those of the detailed chemical reaction mechanism and experiment}

Fig. 10 and Fig. 11 show the mole fraction distributions of major species on the center axis between oxidizer and fuel nozzles obtained by using the FPV and FGM with the numerical solutions of the detailed chemical reaction mechanism and measurements ${ }^{14}$. Since $\mathrm{O}_{2}$ of oxidizer and $\mathrm{CH}_{4}$ of fuel supplied from each nozzle decrease toward the center between the nozzles in all the solutions of the FPV, FGM and detailed chemical reaction mechanism and measurements ${ }^{14}$ and they disappeared around the center between the nozzles (Fig. 10 (a) and Fig. 11 (a)), $\mathrm{O}_{2}$ and $\mathrm{CH}_{4}$ are found to be consumed completely in the region. In contrast, since the mole fractions of $\mathrm{H}_{2} \mathrm{O}$ (Fig. 10 (a) and Fig. 11 (a)), $\mathrm{CO}$ and $\mathrm{CO}_{2}$ (Fig. 10 (b) and Fig. 11 (b)) of products

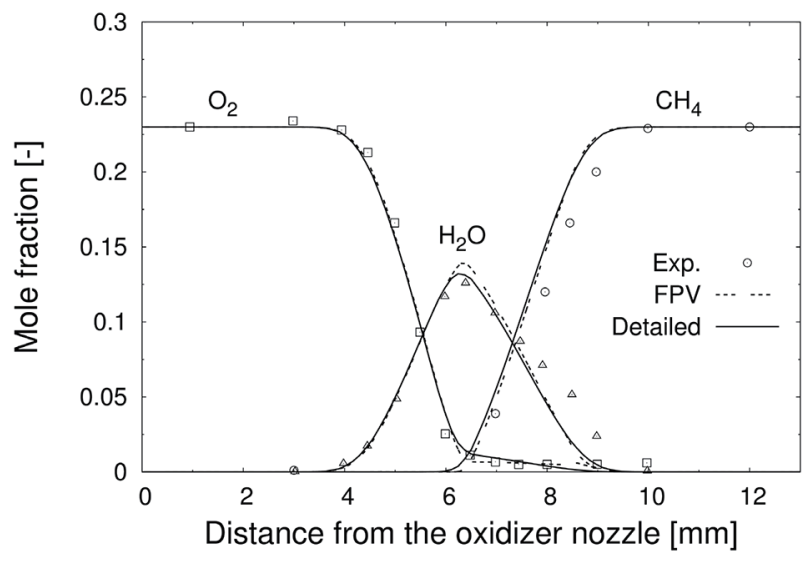

(a) $\mathrm{O}_{2}, \mathrm{CH}_{4}$, and $\mathrm{H}_{2} \mathrm{O}$

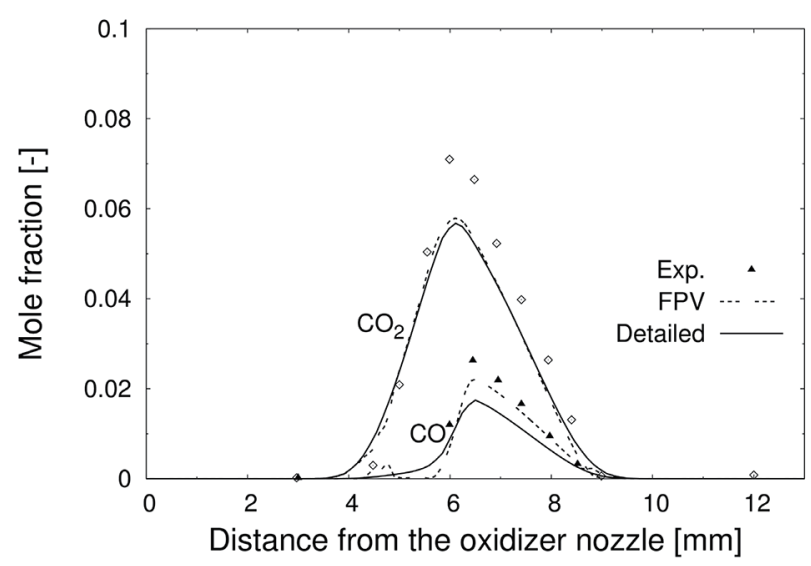

(b) $\mathrm{CO}$ and $\mathrm{CO}_{2}$

Fig. 10 Mole fraction distributions of major species between oxidizer and fuel nozzles obtained with the FPV, the detailed chemical reaction mechanism, and measurements ${ }^{14)}$

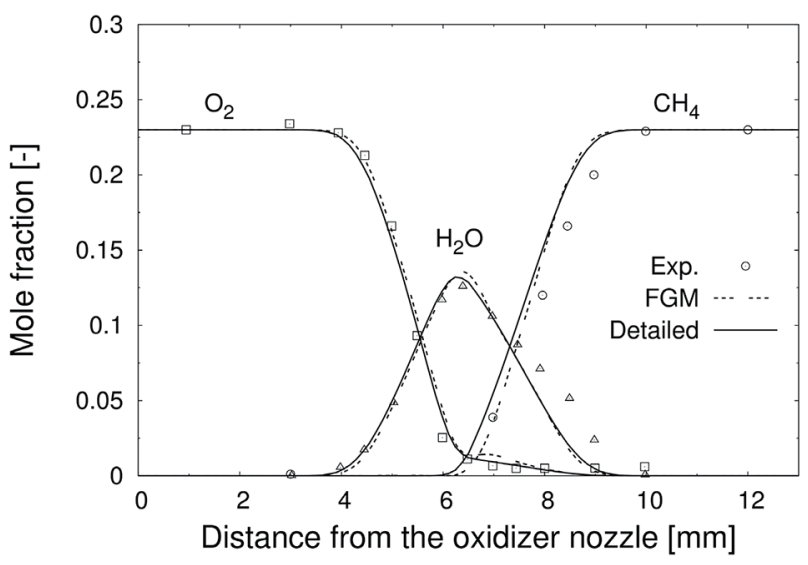

(a) $\mathrm{O}_{2}, \mathrm{CH}_{4}$, and $\mathrm{H}_{2} \mathrm{O}$

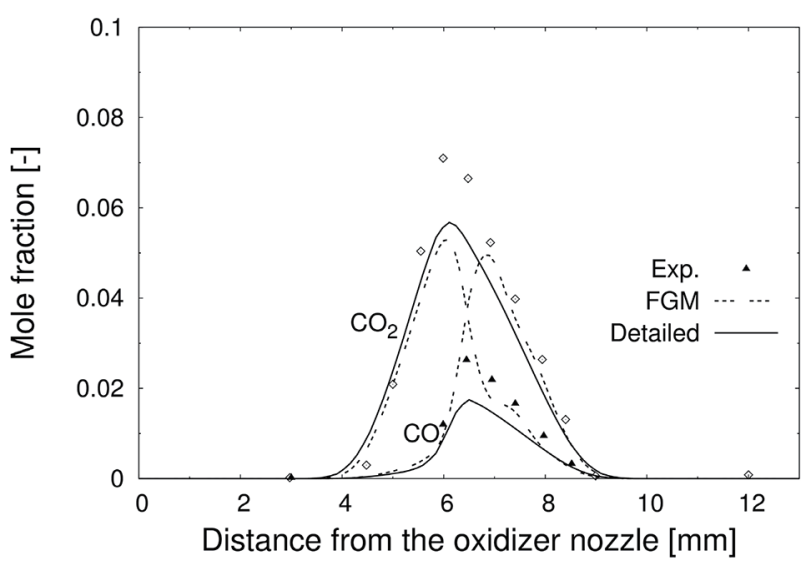

(b) $\mathrm{CO}$ and $\mathrm{CO}_{2}$

Fig. 11 Mole fraction distributions of major species between oxidizer and fuel nozzles obtained with the FGM, the detailed chemical reaction mechanism, and measurements ${ }^{14)}$

increase around center between nozzles, respectively, the combustion reaction progresses in this region. Although, as is indicated in Fig. 10 (a) and (b), the FPV slightly overpredicted the $\mathrm{CH}_{4}$ mole fraction at the fuel side and underpredicted $\mathrm{CO}_{2}$ mole fraction around the center between the nozzles compared with the measurements, it reproduced other major species in the measurements reasonably. Furthermore, the numerical solutions in the FPV almost completely agreed with those in the detailed chemical reaction mechanism in mole fractions of each chemical species. Therefore, it is found that the numerical solutions with the FPV can be obtained with almost the same accuracy of those with the detailed chemical reaction mechanism for the counter-flow diffusion flame. Although there is small discrepancy between the numerical solutions in the FPV and measurements, this could be because the combustion simulation could not be conducted with the equivalent boundary conditions as the experiment, and it is considered that the intended objective to reproduce the 
numerical solutions with the detailed chemical reaction mechanism was achieved. Although not shown here, the combustion simulation with the San Diego Mechanism ${ }^{21)}$ for a detailed chemical reaction mechanism was conducted and the numerical solutions in the mole fraction distributions of major chemical species discussed above were almost the same as those with GRI-Mech 3.0. On the other hand, as shown in Fig. 11 (a) and (b), the FGM represents the measurements in $\mathrm{O}_{2}, \mathrm{CH}_{4}$ and $\mathrm{H}_{2} \mathrm{O}$ mole fractions with the same accuracy as the FPV. However, the FGM overpredicted $\mathrm{CO}$ mole fraction and underpredicted $\mathrm{CO}_{2}$ mole fraction especially in the fuel side compared with the measurements. Moreover, although the numerical solutions in the FGM almost perfectly agreed with those in the detailed chemical reaction mechanism in $\mathrm{O}_{2}, \mathrm{CH}_{4}, \mathrm{H}_{2} \mathrm{O}$ mole fractions, there was significantly large difference in $\mathrm{CO}$ and $\mathrm{CO}_{2}$ mole fraction especially at the fuel side. Therefore, the intended objective to reproduce the numerical solutions in the detailed chemical reaction mechanism cannot be achieved in the combustion simulation with the FGM. The same trend has also been found in the previous study ${ }^{22)}$.

\subsection{Further investigation of $\mathrm{CO}$ and $\mathrm{CO}_{2}$ in the flamelet table of Flamelet/Progress-Variable approach and Flamelet-Generated Manifolds method}

To investigate the cause of the significant difference in the distributions of $\mathrm{CO}$ and $\mathrm{CO}_{2}$ mole fractions in the numerical solutions of the FPV and FGM, Fig. 12 shows the summation of $\mathrm{CO}$ and $\mathrm{CO}_{2}$ mole fractions obtained by the FPV, FGM and measurements ${ }^{14}$. Although the numerical solutions of the FPV and FGM slightly underpredict the maximum value of the measurement, these numerical solutions agree almost perfectly. Also, as shown in Fig. 9, the maximum temperature in the FGM is slightly lower than that in the FPV. Further, as is discussed in Fig. 9,

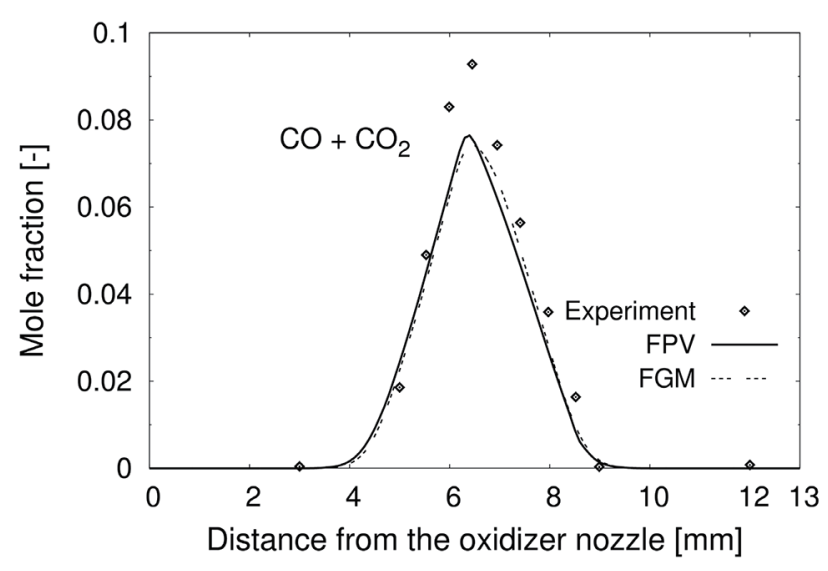

Fig. 12 Mole fraction distributions of the summation of $\mathrm{CO}$ and $\mathrm{CO}_{2}$ obtained by the FPV, FGM, and measurements ${ }^{14)}$ because the normalized value of the reaction progress variable was approximately 0.92 in each combustion model, the combustion reaction sufficiently progresses and almost reaches steady-state. Hereby, Fig. 13 indicates the distributions of $\mathrm{CO}$ and $\mathrm{CO}_{2}$ mole fraction for mixture fractions at the normalized value of the reaction progress variable of 0.92 , which is saved in the flamelet table of the (a) FPV and (b) FGM. Note that the solid line at $Z=0.30$ in Fig. 13 means mixture fraction at stoichiometric ratio. While the maximum values of $\mathrm{CO}$ and $\mathrm{CO}_{2}$ mole fractions exist around mixture fraction of $Z=0.3$ in the flamelet table used in the FPV, the value of $\mathrm{CO}$ exists around $Z=0.45$ and its value is large though the value of $\mathrm{CO}_{2}$ does around $Z=0.30$ in that used in the FGM. From the above facts, the trend that the mole fraction of $\mathrm{CO}$ is higher and that of $\mathrm{CO}_{2}$ is lower especially at the fuel side in the FGM would be because the FGM represents dissociation reaction of $\mathrm{CO}_{2}$ which occurs at high temperature especially in the fuelrich region. Since the flamelet tables are generated for the

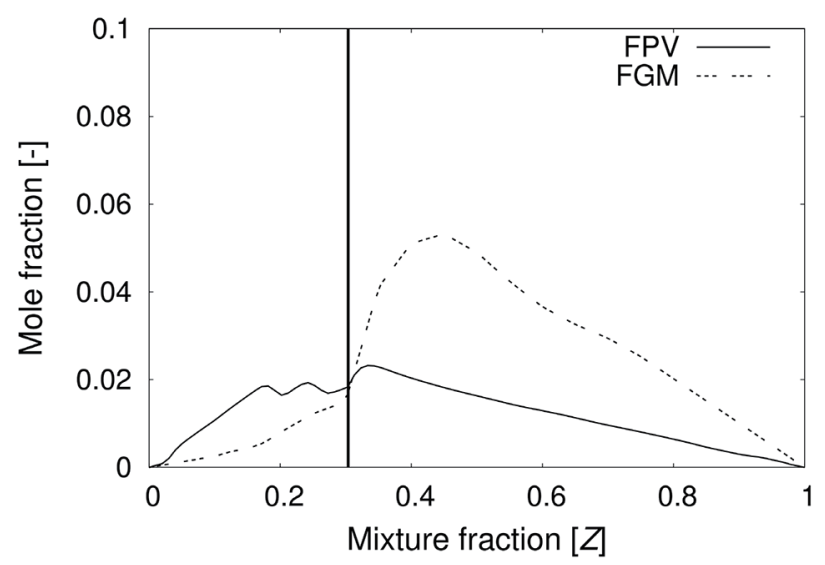

(a) $\mathrm{CO}$

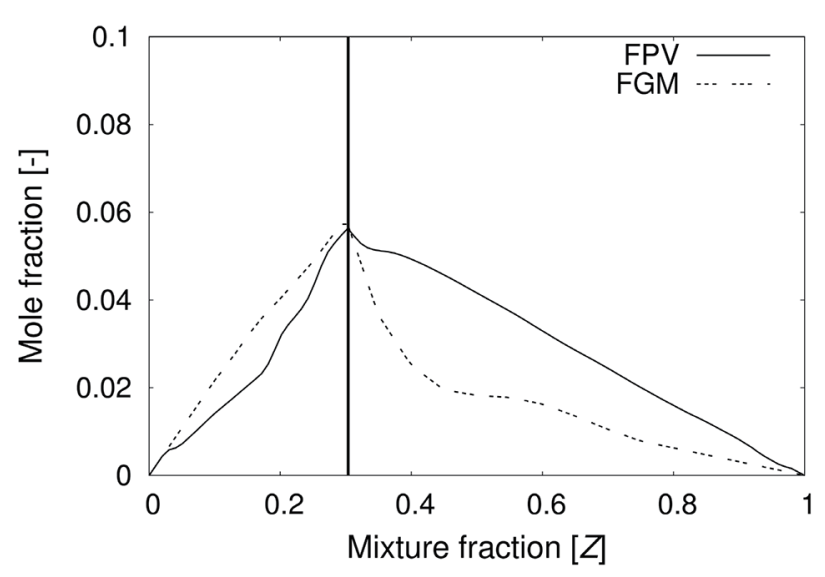

(b) $\mathrm{CO}_{2}$

Fig. $13 \mathrm{CO}$ and $\mathrm{CO}_{2}$ mole fractions for mixture fraction at a reaction progress variable of 0.92 in the flamelet tables generated by the FPV and FGM 
counter-flow diffusion flame in the FPV and the premixed flame in the FGM, respectively, the characteristics of these different flames are reflected in the flamelet table. While diffusion flame reaches steady-state with the mixture receiving the effect of its surroundings with a different equivalence ratio, premixed flame does with the mixture at a constant equivalence ratio in which oxidizer and fuel have already been mixed perfectly. Therefore, in the FGM, the steady-state condition in premixed flame is chemical equilibrium or close to it and dissociation reaction of $\mathrm{CO}_{2}$, which is endothermic reaction, progresses, resulting in higher $\mathrm{CO}$ and lower $\mathrm{CO}_{2}$ mole fractions especially in the fuel-rich region. In addition, the reaction progress variable is defined as summation of $\mathrm{CO}, \mathrm{CO}_{2}, \mathrm{H}_{2}$, and $\mathrm{H}_{2} \mathrm{O}$ mass fraction in this study, and the balance of $\mathrm{CO}$ and $\mathrm{CO}_{2}$ might not be represented because summation of $\mathrm{CO}$ and $\mathrm{CO}_{2}$ is involved in the reaction progress variable.

\section{Conclusions}

This study performed a combustion simulation for the laminar counter-flow diffusion flame by using the Flamelet/Progress-Variable approach (FPV) and FlameletGenerated Manifolds method (FGM) and investigated the characteristics of each model. As a result, the FPV, which uses the flamelet table generated with diffusion flame, successfully reproduced the measurements of the mole fraction distributions of chemical species and their solutions almost perfectly agreed with those in the detailed chemical reaction mechanism. On the other hand, although the solutions of the FGM using the flamelet table generated with premixed flame are in almost perfect agreement with those with detailed chemical reaction mechanism and measurements in the distributions of $\mathrm{O}_{2}, \mathrm{CH}_{4}$ and $\mathrm{H}_{2} \mathrm{O}$ mole fractions, it overpredicted $\mathrm{CO}$ mole fraction and underpredicted $\mathrm{CO}_{2}$ mole fraction especially in the fuel-rich region. This was attributed to the characteristic of the premixed combustion in which the combustion reaction sufficiently progresses and nearly reaches chemical equilibrium state, and $\mathrm{CO}_{2}$ dissociates to $\mathrm{CO}$.

\section{Acknowledgement}

This work was partially supported by JSPS KAKENHI Grant Number 18K03964.

\section{References}

1) Smith, G. P.; Golden, D. M.; Frenklach, M.; Moriarty, N. W.; Eiteneer, B.; Goldenberg, M.; Bowman, C. T.; Hanson, R. K.; Soonho Song, W. C.; Gardiner, J.; Lissianski, V.
V.; Qin, Z., "GRI-Mech 3.0." [Online], available at http:// www.me.berkeley.edu/gri_mech/

2) Peters, N., Prog. Energy Combust. Sci., 10, 319-339 (1984)

3) Peters, N., Symposium (International) on Combustion, 21(1), 1231-1250 (1988)

4) Pierce, C. D.; Moin, P., J. Fluid Mech., 504, $73-97$ (2004)

5) Oijen, J. A. Van; Goey, L. P. H. De, Combust. Sci. Technol., 161, 113-137 (2000)

6) van Oijen, J. A.; Donini, A.; Bastiaans, R. J. M.; ten Thije Boonkkamp, J. H. M.; de Goey, L. P. H., Prog. Energy Combust. Sci., 57, 30-74 (2016)

7) Fiorina, B.; Veynante, D.; Candel, S., Flow, Turbul. Combust., 94, 3-42 (2015)

8) Göktolga, M. U.; van Oijen, J. A.; de Goey, L. P. H., Proc. Combust. Inst., 36, 4269-4277 (2017)

9) Watanabe, J.; Yamamoto, K., Proc. Combust. Inst., 35, 2315-2322 (2015)

10) Watanabe, J.; Okazaki, T.; Yamamoto, K.; Kuramashi, K.; Baba, A., Proc. Combust. Inst., 36, 2155-2163 (2017)

11) Akaotsu, S.; Matsushita, Y.; Aoki, H.; Malalasekera, W., Adv. Powder Technol., 31, 1302-1322 (2020)

12) Knudsen, E.; Pitsch, H., Combust. Flame, 159, 242-264 (2012)

13) Wen, X.; Luo, Y.; Luo, K.; Jin, H.; Fan, J., Fuel, 188, 661$671(2017)$

14) Sung, C. J.; Liu, J. B.; Law, C. K., Combust. Flame, 102, 481-492 (1995)

15) Pitsch, H., "FlameMaster: A $\mathrm{C}++$ program package for 0D combustion and 1D laminar flame calculations," Institut für Technische Mechanik, RWTH, Aachen [Online], available at https://www.itv.rwth-aachen.de/ en/downloads/flamemaster/

16) Matsushita, Y.; Malalasekera, W.; Yokoi, S.; Saito, Y.; Aoki, H., Kinzoku, 85, 915-921 (2015)

17) Roe, P. L., Annu. Rev. Fluid Mech., 18, 337-365 (1986)

18) Patankar, S. V; Spalding, D. B., Int. J. Heat Mass Transf., 15, 1787-1806 (1972)

19) Rhie, C. M.; Chow, W. L., AIAA J., 21, 1525-1532 (1983)

20) Amsden, A. A.; Harlow, F. H., The SMAC method: A numerical technique for calculating incompressible fluid flows, (1970)

21) 'Chemical-Kinetic Mechanisms for Combustion Applications', San Diego Mechanism web page, Mechanical and Aerospace Engineering (Combustion Research), University of California at San Diego [Online], available at http://combustion.ucsd.edu

22) Verhoeven, L. M.; Ramaekers, W. J. S.; van Oijen, J. A.; de Goey, L. P. H., Combust. Flame, 159, 230-241 (2012) 